\title{
Aplikasi Metode Third Molar Maturity Index pada Kelompok Usia Remaja
}

\author{
Yoghi B. Prabowo, ${ }^{1 *}$ Haliza Ermanto, ${ }^{1 *}$ Tira H. Skripsa, ${ }^{1}$ Edward K. S. Limijadi, ${ }^{2}$ \\ Rizky M. Boedi ${ }^{1}$
}

\author{
${ }^{1}$ Departemen Kedokteran Gigi Fakultas Kedokteran Universitas Diponegoro Semarang \\ ${ }^{2}$ Departemen Patologi Klinik Fakultas Kedokteran Universitas Diponegoro Semarang \\ * Kedua Penulis memiliki kontribusi yang sama dalam penulisan naskah. \\ Email: rizkymerdietio@lecturer.undip.ac.id
}

\begin{abstract}
Up to now, there are still residents of Indonesia who do not have legal documents supporting age information. Hence, proving the age of a person concerning some reasons becomes difficult. Third molar development could be used as an indicator to estimate the age in adolescents if legal documents are not available. This study was aimed to prove the difference in the development of third molars between individuals aged above and below 19 years using the third molar maturity index (I3M) method. Third molar development calculations were performed on 112 digital OPG photographs (71 females and 41 males) of patients aged 16- <24 years. Samples were divided into two age groups, namely $<19$ years and $\geq 19$ years. We performed comparison tests to analyze the differences between groups and genders against I3M. The results showed significant differences between the development of third molars in individuals aged above and below 19 years according to I3M values. Meanwhile, there was no significant differences in I3M values between males and females. Males experienced faster third molar development than females in the age group $<19$ years. In conclusion, the I3M method can be used to differentiate the development of third molars in individuals aged above and below 19 years. Further research could be carried out by using a larger number of samples and setting a threshold of I3M for the age of 19 among Indonesian population.
\end{abstract}

Keywords: dental age estimation, third molar, I3M method

\begin{abstract}
Abstrak: Pada saat ini, masih ada penduduk Indonesia yang tidak memiliki dokumen legal pendukung informasi usia sehingga terdapat kesulitan dalam membuktikan usia seseorang untuk berbagai kebutuhan. Pertumbuhan molar ketiga dapat digunakan sebagai indikator untuk melakukan estimasi usia pada remaja bila dokumen legal tidak tersedia. Penelitian ini bertujuan untuk membuktikan perbedaan pertumbuhan molar ketiga pada individu berusia di atas dan di bawah 19 tahun dengan metode third molar maturity index $\left(\mathrm{I}_{3} \mathrm{M}\right)$. Perhitungan pertumbuhan molar ketiga dilakukan pada 112 foto OPG digital (71 wanita dan 41 pria) dari pasien berusia 16-<24 tahun. Sampel dibagi menjadi dua kelompok usia, yaitu $<19$ tahun dan $\geq 19$ tahun. Uji beda dilakukan untuk menganalisis perbedaan antar kelompok dan jenis kelamin terhadap $\mathrm{I}_{3} \mathrm{M}$. Hasil penelitian ini menunjukkan perbedaan bermakna antara pertumbuhan molar ketiga pada individu berusia di atas dan di bawah 19 tahun. Tidak terdapat perbedaan bermakna pada nilai $\mathrm{I}_{3} \mathrm{M}$ pada pria dan wanita. Pria ditemukan mengalami pertumbuhan molar ketiga yang lebih cepat dari wanita pada kelompok usia $<19$ tahun. Simpulan penelitian ini ialah metode $\mathrm{I}_{3} \mathrm{M}$ dapat digunakan untuk membedakan pertumbuhan molar ketiga pada individu berusia di atas dan di bawah 19 tahun. Disarankan penelitian lanjut dengan menggunakan jumlah sampel yang lebih besar dan dilakukan penetapan batas ambang $\mathrm{I}_{3} \mathrm{M}$ untuk usia 19 tahun pada populasi Indonesia.
\end{abstract}

Kata kunci: estimasi usia dental, molar ketiga, metode I3M 


\section{PENDAHULUAN}

Batas usia perkawinan di Indonesia mengalami perubahan melalui UndangUndang Nomor 16 Tahun 2019 menjadi 19 tahun untuk pria dan wanita. Perubahan ini meningkatkan batas minimal usia perkawinan bagi wanita yang semula 16 tahun menjadi 19 tahun. $^{1}$ Pertimbangan terkait perubahan ini ialah perkawinan pada usia anak dapat memberikan dampak negatif terutama bagi wanita dalam hal kesehatan, pekerjaan, dan kebebasan untuk melanjutkan pendidikan. ${ }^{2}$ Usia individu yang menjadi dasar pernikahan dapat diperiksa melalui dokumen legal seperti Kartu Tanda Penduduk (KTP) dan akta kelahiran, ${ }^{3}$ namun, masih terdapat penduduk Indonesia yang belum memiliki dokumen legal tersebut. ${ }^{4,5}$ Analisis estimasi usia dibutuhkan apabila dokumen legal tidak tersedia untuk suatu kepentingan seperti kasus kriminal dan penentuan batas usia perkawinan. ${ }^{6-8}$

Pertumbuhan molar ketiga merupakan salah satu indikator utama untuk melakukan analisis estimasi usia pada remaja. Molar ketiga ialah satu-satunya gigi yang masih mengalami proses maturasi pada usia 16-24 tahun. ${ }^{9}$ Cameriere et al $^{10}$ (2008) mengembangkan metode third molar maturity index $\left(\mathrm{I}_{3} \mathrm{M}\right)$ untuk menilai pertumbuhan molar ketiga dengan menjumlahkan jarak akar gigi yang terbuka dibagi dengan panjang gigi pada radiografi orthopantomograph (OPG). Nilai ambang yang ditetapkan oleh penelitian tersebut dinilai lebih akurat dalam membedakan individu berusia di atas dan di bawah 18 tahun daripada metode Demirjian dan dianggap andal untuk diterapkan di berbagai populasi dan batasan usia. ${ }^{10-13}$

Integrasi analisis estimasi usia pada individu yang berkaitan dengan kepentingan proses hukum dan peradilan di Indonesia masih belum banyak dilakukan dan belum ada penelitian yang melakukan evaluasi penggunaan metode ini untuk menilai pertumbuhan molar ketiga pada populasi Indonesia dan pada batas usia 19 tahun. Berdasarkan hal tersebut maka dilakukan penelitian ini yang bertujuan untuk melihat kemampuan metode $\mathrm{I}_{3} \mathrm{M}$ dalam membedakan pertumbuhan molar ketiga pada indi- vidu berusia di atas dan di bawah 19 tahun.

\section{METODE PENELITIAN}

Penelitian ini menggunakan jenis penelitian observasional analitik. Foto OPG digital dari 112 individu (71 wanita dan 41 pria) berusia $16,00-<24$ tahun dipilih secara retrospektif diperoleh dari Laboratorium Klinik Pramita, Semarang, Indonesia pada periode pengambilan foto tahun 2016 hingga 2020. Variabel usia selanjutnya dibagi menjadi dua kelompok yaitu di atas 19 tahun dan di bawah 19 tahun. Usia di atas 19 tahun yang dimaksud adalah usia 19- <24 tahun dan usia di bawah 19 tahun adalah 16$<19$ tahun. Usia subjek penelitian dihitung dari tanggal lahir subjek hingga tanggal foto OPG diambil. Ethical clearance didapatkan dari Komisi Etik Penelitian Kesehatan Fakultas Kedokteran Universitas Diponegoro No. 139/EC/KEPK/FK-UNDIP/VI/ 2020.

Foto OPG digital yang digunakan dalam penelitian ini ialah foto OPG digital dengan ketajaman dan kontras yang baik pada gigi molar ketiga kiri mandibula. Kriteria eksklusi penelitian ini ialah foto OPG digital dengan gigi molar ketiga kiri mandibula agenesis, dicabut, mengalami anomali pertumbuhan, angulasi ke arah bukal atau lingual, dan dilakukan perawatan saluran akar atau restorasi. Keterbatasan jumlah foto OPG digital dengan gigi molar ketiga kiri mandibula yang memenuhi kriteria inklusi menyebabkan penggunaan gigi molar ketiga kanan mandibula pada 6 foto OPG digital sebagai sampel penelitian. Hal ini dapat dilakukan karena gigi yang sama yang terletak pada rahang yang sama dapat saling menggantikan satu sama lain. ${ }^{14}$

Data subjek penelitian yang didapatkan meliputi nomor registrasi, tanggal lahir, tanggal pengambilan foto OPG, dan jenis kelamin. Data subjek dijamin kerahasiaannya dan hanya digunakan untuk kepentingan penelitian serta pengembangan ilmu pengetahuan tanpa ada kemungkinan untuk mengidentifikasi identitas subjek tersebut.

Foto OPG digital kemudian diproses dengan software Adobe Photoshop CC 2020. Seluruh sampel penelitian dihitung besar nilai $\mathrm{I}_{3} \mathrm{M}$ oleh pengamat pertama $(\mathrm{HE})$ 


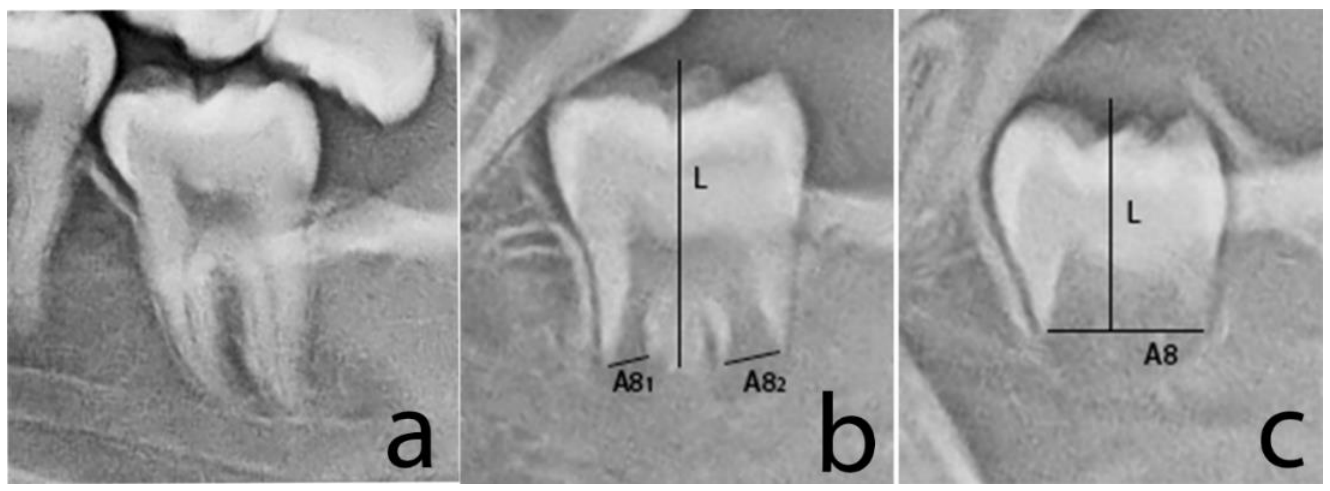

Gambar 1. Contoh pengukuran dengan metode third molar maturity index $\left(\mathrm{I}_{3} \mathrm{M}\right)$. Pertumbuhan akar telah selesai, $\mathrm{I}_{3} \mathrm{M}=0$ (a); pertumbuhan molar ketiga dengan bifurkasi yang telah terbentuk, I3M = $\frac{A 81+A 82}{L}$ (b); pertumbuhan molar ketiga dengan bifurkasi yang belum terbentuk, I3M $=\frac{A 8}{L}$ (c).

tanpa mengetahui usia subjek penelitian. Pengamat pertama dan pengamat kedua (RMB) melakukan perhitungan nilai $\mathrm{I}_{3} \mathrm{M}$ pada $10 \%$ foto OPG digital yang dipilih secara acak dua minggu setelah perhitungan pertama. HE belum pernah melakukan analisis estimasi usia sebelumnya sedangkan RMB telah memiliki pengalaman selama tiga tahun dalam melakukan analisis estimasi usia. Gigi yang telah menyelesaikan pertumbuhan akar gigi memiliki nilai $\mathrm{I}_{3} \mathrm{M}=$ 0 . Nilai $\mathrm{I}_{3} \mathrm{M}$ dihitung dengan cara menjumlahkan jarak tepi dalam $\left(A_{8}=A_{8} 1+A_{8} 2\right)$ dibagi dengan panjang gigi $(L)$ yang diukur dari ujung apikal hingga titik tertinggi dari mahkota $\left(I_{3} M=\frac{A 8}{L}\right)$. Bila pada gigi molar tersebut belum terbentuk bifurkasi, maka jarak antara tepi dalam mahkota dianggap sebagai jarak ujung apikal $\left(A_{8}\right)$ (Gambar 1$)$. Analisis data dimulai dengan uji Intraclass
Correlation Coefficient (ICC) untuk menilai reliabilitas intra-rater dan inter-rater. Selanjutnya, dilakukan uji normalitas Kolmogorov-Smirnov dan uji homogenitas Levene. Analisis korelasi antara usia dan $\mathrm{I}_{3} \mathrm{M}$ dilakukan dengan uji korelasi Spearman. Uji beda Mann Whitney dilakukan untuk menganalisis perbedaan antar kelompok dan jenis kelamin terhadap $\mathrm{I}_{3} \mathrm{M}$.

\section{HASIL PENELITIAN}

Tabel 1 memperlihatkan distribusi sampel penelitian berdasarkan rentang usia dan jenis kelamin. Dari 112 foto OPG digital yang didapatkan, jumlah sampel pria sebanyak 41 foto dan wanita sebanyak 71 foto. Pada masing-masing rentang usia terdapat 14 foto OPG digital. Penutupan akar pertama kali ditemukan pada pria di usia 18 tahun dan wanita di usia 19 tahun.

Tabel 1. Distribusi sampel berdasarkan rentang usia dan jenis kelamin. Angka yang berada di dalam tanda kurung memperlihatkan jumlah sampel yang memiliki $\mathrm{I}_{3} \mathrm{M}=0$

\begin{tabular}{cccc}
\hline $\begin{array}{c}\text { Usia } \\
\text { tahun) }\end{array}$ & Pria & $\begin{array}{c}\text { Jenis Kelamin } \\
\text { Wanita }\end{array}$ & Total \\
\hline $16-<17$ & 7 & 7 & 14 \\
$17-<18$ & 7 & 7 & 14 \\
$18-<19$ & $6(2)$ & 8 & 14 \\
$19-<20$ & $5(1)$ & $9(3)$ & 14 \\
$20-<21$ & $3(1)$ & $11(3)$ & 14 \\
$21-<22$ & $4(3)$ & $10(7)$ & 14 \\
$22-<23$ & $4(3)$ & $10(3)$ & 14 \\
$23-<24$ & $5(5)$ & $9(5)$ & 14 \\
Total & 41 & 71 & 112 \\
\hline
\end{tabular}


Tabel 2 memperlihatkan distribusi usia berdasarkan jenis kelamin dan kelompok nilai $\mathrm{I}_{3} \mathrm{M}$. Rerata usia pria dan wanita pada setiap kelompok nilai $\mathrm{I}_{3} \mathrm{M}$ tidak menunjukkan adanya perbedaan bermakna, kecuali pada kelompok $\mathrm{I}_{3} \mathrm{M}$ 0,08-0,10 ( $\left.\mathrm{p}<0,05\right)$. Rerata usia pria pada setiap kelompok nilai $\mathrm{I}_{3} \mathrm{M}$ lebih kecil jika dibandingkan dengan rerata usia wanita, kecuali pada kelompok nilai $\mathrm{I}_{3} \mathrm{M}$ 0,00-0,02. Hal ini menujukkan pria mengalami proses maturasi akar yang lebih cepat dari wanita.
Hasil uji ICC menunjukkan reliabilitas intra-rater dan inter-rater yang sangat baik yaitu 0,967 dan $0,952 .{ }^{15}$ Uji normalitas Kolmogorov-Smirnov dan uji homogenitas Levene menunjukkan signifikansi sebesar $\mathrm{p}$ $<0,05$ yang menandakan data terdistribusi tidak normal dan heterogen. Usia dan nilai $\mathrm{I}_{3} \mathrm{M}$ memiliki nilai korelasi sebesar $-0,598$ yang memperlihatkan adanya korelasi negatif yang sedang $(\mathrm{p}<0,001) .{ }^{16}$ Gambar 2 memperlihatkan diagram boxplot antara usia dan kelompok nilai $\mathrm{I}_{3} \mathrm{M}$ pada pria dan wanita.

Tabel 2. Distribusi usia berdasarkan jenis kelamin dan kelompok nilai $\mathrm{I}_{3} \mathrm{M}$

\begin{tabular}{|c|c|c|c|c|c|c|c|c|c|c|c|}
\hline \multirow[b]{2}{*}{$\mathbf{I}_{3} \mathbf{M}$} & \multirow[b]{2}{*}{$\mathrm{N}$} & \multicolumn{3}{|c|}{ Pria } & \multicolumn{7}{|c|}{ Wanita } \\
\hline & & $\begin{array}{c}\text { Mean } \pm \\
\text { SD }\end{array}$ & Min & Median & Max & $\mathrm{N}$ & $\begin{array}{c}\text { Mean } \pm \\
\text { SD }\end{array}$ & Min & Median & Max & $\mathrm{p}$ \\
\hline $0,00-0,02$ & 17 & $\begin{array}{c}21,80 \pm \\
1,59\end{array}$ & 18,72 & 22,17 & 23,55 & 25 & $\begin{array}{c}21,80 \pm \\
1,36\end{array}$ & 19,12 & 21,77 & 23,77 & 1,000 \\
\hline $0,02-0,04$ & 2 & $\begin{array}{c}19,56 \pm \\
1,04\end{array}$ & 18,82 & 19,56 & 20,30 & 4 & $\begin{array}{c}19,70 \pm \\
0,79\end{array}$ & 18,80 & 19,64 & 20,74 & 0,860 \\
\hline $0,04-0,08$ & 2 & $\begin{array}{c}19,74 \pm \\
0,71\end{array}$ & 19,24 & 19,74 & 20,25 & 12 & $\begin{array}{c}21,07 \pm \\
1,86\end{array}$ & 17,66 & 21,94 & 23,28 & 0,351 \\
\hline $0,08-0,10$ & 14 & $\begin{array}{c}17,94 \pm \\
0,98\end{array}$ & 16,28 & 17,89 & 19,41 & 16 & $\begin{array}{c}19,90 \pm \\
2,18\end{array}$ & 16,12 & 20,53 & 23,60 & 0,004 \\
\hline $0,10-0,70$ & 6 & $\begin{array}{c}16,80 \pm \\
0,56\end{array}$ & 16,14 & 16,74 & 17,54 & 14 & $\begin{array}{c}17,49 \pm \\
1,06\end{array}$ & 16,17 & 17,38 & 19,74 & 0,153 \\
\hline
\end{tabular}

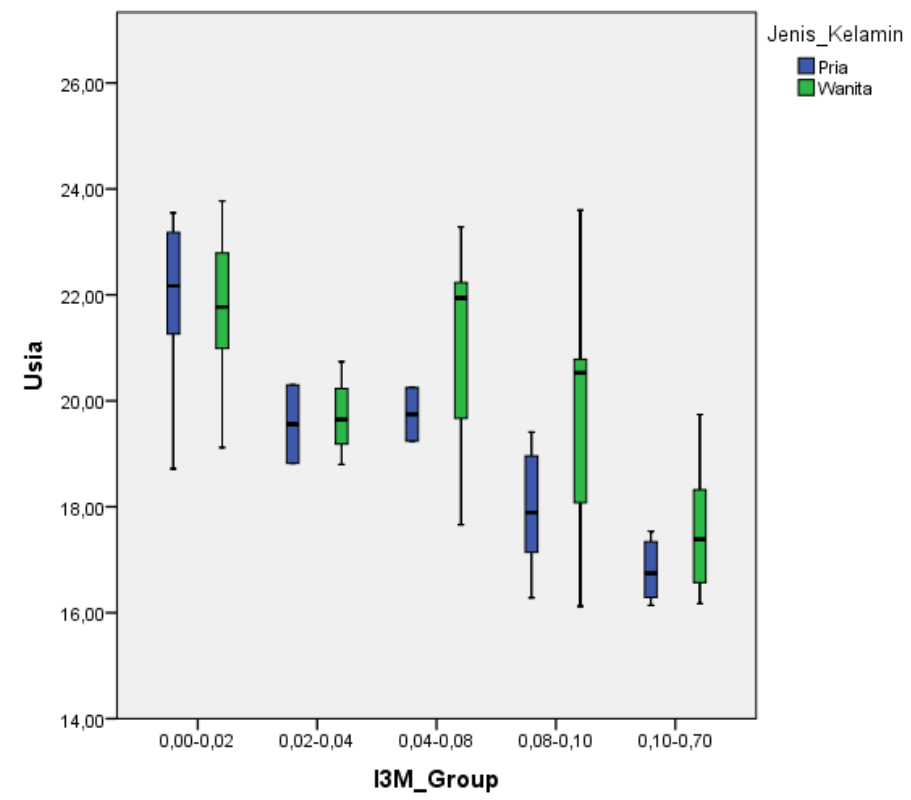

Gambar 2. Hubungan antara usia dan kelompok nilai $\mathrm{I}_{3} \mathrm{M}$. Diagram boxplot memperlihatkan median dan kisaran interkuartil, sedangkan garis Whisker membentang dari box ke arah usia minimun dan maksimum. 
Uji beda Mann-Whitney terhadap variabel $\mathrm{I}_{3} \mathrm{M}$ dan usia menujukkan signifikansi sebesar $\mathrm{p}<0,05$ yang menandakan adanya perbedaan bermakna antara nilai $\mathrm{I}_{3} \mathrm{M}$ pada individu berusia di atas dan di bawah 19 tahun. Hasil uji beda terhadap variabel $\mathrm{I}_{3} \mathrm{M}$ dan jenis kelamin menunjukkan tidak terdapat perbedaan bermakna antara nilai $\mathrm{I}_{3} \mathrm{M}$ pada pria maupun wanita secara umum ( $\mathrm{p}>0,05)$. Sub-analisis variabel nilai $\mathrm{I}_{3} \mathrm{M}$ dan jenis kelamin terhadap kelompok usia menunjukkan perbedaan bermakna pada kelompok usia $<19$ tahun $(\mathrm{p}<0,05)$, tetapi tidak bermakna pada kelompok usia $\geq 19$ tahun ( $p>0,05)$. Metode $\mathrm{I}_{3} \mathrm{M}$ mampu untuk membedakan pertumbuhan molar ketiga pada individu berusia di atas dan di bawah 19 tahun.

\section{BAHASAN}

Proses pertumbuhan gigi telah banyak diteliti dan digunakan untuk melakukan analisis estimasi usia. ${ }^{10,14,17}$ Pertumbuhan gigi dilaporkan lebih sedikit terpengaruh oleh faktor eksternal dibandingkan dengan pertumbuhan skeletal. ${ }^{18}$ Identifikasi forensik menggunakan gigi telah banyak digunakan untuk identifikasi korban kasus bencana di Indonesia. ${ }^{19,20}$ Namun, aplikasi ilmu odontologi forensik yang berkaitan dengan individu hidup untuk kepentingan lembaga hukum dan peradilan masih belum banyak dilakukan. Pada penelitian ini, diketahui terdapat perbedaan antara pertumbuhan molar ketiga pada individu berusia di atas dan di bawah 19 tahun yang dihitung dengan metode $\mathrm{I}_{3} \mathrm{M}$.

Perbedaan nilai $\mathrm{I}_{3} \mathrm{M}$ pada pria maupun wanita secara umum pada penelitian ini ditemukan tidak bermakna. Hal ini sesuai dengan penelitian yang dilakukan di Belanda dan beberapa negara lainnya yang melaporkan bahwa tidak ada perbedaan proses maturasi akar molar ketiga antara pria dan wanita. ${ }^{11,21,22}$ Namun, bila dilakukan sub-analisis pada masing-masing kelompok usia, didapatkan perbedaan bermakna antara nilai $\mathrm{I}_{3} \mathrm{M}$ pada pria dan wanita kelompok usia <19 tahun dengan pria mengalami proses maturasi akar lebih cepat daripada wanita. Hal ini sesuai dengan beberapa penelitian yang telah dilakukan sebelumnya. ${ }^{23,24}$ Namun, hasil ini bertentangan dengan penelitian yang dilakukan oleh Liversidge et al yang melaporkan bahwa pertumbuhan molar ketiga lebih cepat pada wanita dibandingkan pria. Peran jenis kelamin dalam perkembangan molar ketiga hingga saat ini masih belum dipahami seutuhnya. ${ }^{25}$ Oleh karena itu, perbedaan pertumbuhan molar ketiga pada pria dan wanita harus dianalisis terlebih dahulu pada setiap penelitian.

Hasil uji ICC pada penelitian ini menunjukkan reliabilitas yang sangat baik meskipun terdapat perbedaan pengalaman dalam melakukan analisis estimasi usia antara HE dan RMB (pengamat pertama dan kedua). Ribier et $\mathrm{al}^{24}$ melaporkan bahwa metode $\mathrm{I}_{3} \mathrm{M}$ memperlihatkan reliabilitas intra-rater dan inter-rater yang sangat baik meskipun kedua pengamat baru pertama kali menggunakan metode ini untuk analisis estimasi usia. Dari hal tersebut dapat diketahui bahwa metode $\mathrm{I}_{3} \mathrm{M}$ memperlihatkan reproduksibilitas yang sangat baik dan bebas dari pengaruh pengalaman pengamat. Penelitian ini menerapkan prosedur kontrol yang ketat terhadap kedua pengamat dengan mengikuti satu protokol yang telah ditetapkan bersama. Protokol tersebut meliputi penggunaan aplikasi yang sama untuk memroses foto, pengamat tidak boleh melakukan perhitungan antar sampel dengan alat yang berbeda, kecerahan layar dari alat diatur konstan, dan perhitungan sampel dibatasi sejumlah 10 foto OPG digital per hari untuk menghindari kelelahan pada mata dan ketidaktepatan pada perhitungan. Keterbatasan jumlah sampel yang diteliti menyebabkan penelitian ini tidak dapat melakukan uji analisis regresi logistik untuk menetapkan nilai ambang batas $\mathrm{I}_{3} \mathrm{M}$ pada usia 19 tahun. Selain itu, nilai ambang $\mathrm{I}_{3} \mathrm{M}<0,08$ untuk usia 18 tahun juga tidak dapat diuji aplikasinya pada batas usia 19 tahun untuk populasi Indonesia pada penelitian ini.

\section{SIMPULAN}

Metode $\mathrm{I}_{3} \mathrm{M}$ dapat digunakan untuk membedakan pertumbuhan molar ketiga pada individu berusia di atas dan di bawah 
19 tahun. Disarankan untuk melakukan penelitian lebih lanjut untuk menentukan nilai ambang batas $\mathrm{I}_{3} \mathrm{M}$ bagi usia 19 tahun pada populasi Indonesia. Nilai ambang batas tersebut diharapkan dapat menjadi salah satu cara untuk menetapkan usia anak sebagai dokumen legal untuk berbagai kepentingan antara lain mencegah terjadinya perkawinan usia anak bagi individu yang tidak memiliki dokumen legal.

\section{Konflik Kepentingan}

Penulis menyatakan tidak ada konflik kepentingan dalam penelitian ini.

\section{Ucapan Terima Kasih}

Penelitian ini didanai sepenuhnya oleh Hibah Penelitian Fakultas Kedokteran, Universitas Diponegoro, No.85/UN.7.6.4.2/ HK/2020.

Penulis mengucapkan terima kasih kepada dr. Sigid Kirana Lintang Bhima, $\operatorname{Sp} . \mathrm{FM}(\mathrm{K})$ atas masukannya dalam bidang legal dan hukum Indonesia.

\section{DAFTAR PUSTAKA}

1. RI. Undang-Undang Nomor 16 Tahun 2019 tentang Perubahan atas Undang-Undang Nomor 1 Tahun 1974 tentang Perkawinan. 2019.

2. Arthur M,Earle A, Raub A, Vincent I, Atabay E, Latz I, et al.Child marriage laws around the world: minimum marriage age, legal exceptions, and gender disparities. J Women Polit Policy. 2018;39(1):51-74.

3. Adserias-Garriga J, editor. Age Estimation: A Multidisciplinary Approach. London: Elsevier Inc; 2019.

4. Kementerian Dalam Negeri RI. Laporan Kinerja Kemendagri 2018. Jakarta, 2018. Available from: https://www. kemendagri.go.id/arsip/detail/9165.

5. Badan Pusat Statistik. Persentase Anak yang Memiliki Akta Kelahiran Menurut Provinsi Tahun 2015 - 2016. Available from: https://www.bps.go.id/dynamic table/2018/06/28/1496/persentase-anakyang-memiliki-akta-kelahiran-menurutprovinsi-2015---2016.html.

6. Focardi M, Pinchi V, De Luca F, Norelli GA. Age estimation for forensic purposes in Italy: Ethical issues. Int $\mathbf{J}$ Legal Med. 2014;128(3):515-22.
7. Sykes L, Bhayat A, Bernitz H. The effects of the refugee crisis on age estimation analysis over the past 10 years: A 16-country survey. Int J Environ Res Public Health. 2017;14(6):630.

8. Schemeling A, Grundmann C, Fuhrmann A. Criteria for age estimation in living individuals. Int J Leg Med. 2008;(122): 457-60.

9. Schemeling A, Gramendi P, Prieto J, Landa M. Forensic Age Estimation in Unaccompanied Minors and Young Living Adults. In: Vieira D, editor. Forensic Medicine From Old Problems to New Challenges. Rijeka: InTech, 2011; p. 77-120.

10. Cameriere R, Ferrante L, De Angelis D, Scarpino F, Galli F. The comparison between measurement of open apices of third molars and Demirjian stages to test chronological age of over 18 year olds in living subjects. Int J Legal Med. 2008; 122(6):493-7.

11. Cavrić J, Galić I, Vodanović M, Brkić H, Gre gov J, Serena Viva S, et al. Third molar maturity index (I3M) for assessing age of majority in a black African population in Botswana. Int J Legal Med. 2016;130(4): 1109-20.

12. Balla SB, Chinni SS, Galic I, Alwala AM, Machani P, Cameriere R. A cut-off value of third molar maturity index for indicating a minimum age of criminal responsibility: Older or younger than 16 years? J Forensic Leg Med. 2019;65:108-12.

13. Różyło-Kalinowska I, Kalinowski P, Kozek M, Galić I, Cameriere R. Validity of the third molar maturity index I3M for indicating the adult age in the Polish population. Forensic Sci Int. 2018; 290:352.e1-352.e6.

14. Demirjian A, Goldstein H, Tanner J. A new system of dental age assessment. Hum Biol. 1973;45(2):211-27.

15. Perinetti G. StaTips Part IV: Selection, interpretation and reporting of the intraclass correlation coefficient. South Eur J Orthod Dentofac Res. 2018;5(1):3-5.

16. Schober P, Schwarte LA. Correlation coefficients: Appropriate use and interpretation. Anesth Analg. 2018;126(5):1763-8.

17. AlQahtani SJ, Hector MP, Liversidge HM. Brief communication: The London atlas of human tooth development and eruption. Am J Phys Anthropol. 2010; 142(3): 481-90. 
18. Conceição ELN, Cardoso HFV. Environmental effects on skeletal versus dental development II: Further testing of a basic assumption in human osteological research. Am J Phys Anthropol. 2011; 144(3):463-70.

19. Soedarsono N, Untoro E, Quendangen A, Atmadja D. The role of forensic odontology in personal identification: Indonesian Perspective. Indones J Leg Forensic Sci. 2008;1(1):282195.

20. Prawestiningtyas E, Algozi AM. Forensic identification based on both primary and secondary examination priority in victim identifiers on two different mass disaster cases (Identifikasi forensik berdasarkan pemeriksaan primer dan sekunder sebagai penentu identitas korban pada dua kasus). J Kedokt Brawijaya. 2009;XXV(2):87-94.

21. Boyacıoğlu Doğru $H$, Gulsahi A, Burçak Çehreli S, Galić I, van der Stelt P, Cameriere R. Age of majority assessment in Dutch individuals based on Cameriere's third molar maturity index. Forensic Sci Int. 2018;282:231.e1-231.e6.

22. Zelic K, Galic I, Nedeljkovic N, Jakovljevic A, Milosevic O, Djuric M, et al. Accuracy of Cameriere's third molar maturity index in assessing legal adulthood on Serbian population. Forensic Sci Int. 2016;259: 127-32.

23. Galić I, Lauc T, Brkić H, Vodanović M, Galić E, Biazevic MGH, et al. Cameriere's third molar maturity index in assessing age of majority. Forensic Sci Int. 2015;252: 191.e1-191.e5.

24. Ribier L, Saint-Martin P, Seignier M, Paré A, Brunereau L, Rérolle C. Cameriere's third molar maturity index in assessing age of majority: a study of a French sample. Int J Legal Med. 2020;134(2):783-92.

25. Levesque GY, Demirjian A, Tanguay R. Sexual dimorphism in the development, emergence, and agenesis of the mandibular third molar. J Dent Res. 1981; 60(10):1735-41. 